\title{
Studies on the Evolution and Value of the Item Setting of the Summer Olympic Games
}

\author{
Tao Liu \\ Sports Sociology and Humanities, School of Sports Science, Nantong University, Nantong 226019, China
}

\begin{abstract}
The Olympic Games, as the global sports event, attract many countries in the world to participate in and they always take obtaining the right of holding it as the pride of the country. With the constant development of the Olympic Games, people have proposed higher requirements for it and the reformation is eagerly needed and the reformation is mainly concentrated on the item setting. According to a large amount of theoretical research to the item setting of Olympic Games in academia, there is big issue about the item setting for the current Summer Olympic Games which has sustained for a long time. Its practical representations are the contradiction between narrowing the scope of the Olympic Games and borrowing in the new items and the contradiction of gender equality in item setting and also the contradiction of balancing the business value and social value. Therefore, this thesis will mainly study on the evolution and value of the item setting of the Summer Olympic Games and propose reasonable improvement measures for the issue of the item setting, combining with the practical conditions, and thus to better promote the sustain development of the Summer Olympic Games.
\end{abstract}

Key words: The Summer Olympic Games, item setting, evolution history, value research.

The Olympic Games is the worldwide sports event. With the updating and improvement of sports events, new events have been introduced in constantly and also some old events have been excluded. In February, 2013, International Olympic Committee (IOC) issued a statement that the event of wresting will be excluded in the Summer Olympic Games of 2020 and the 26 events of Olympic Games will become 25. And before the wresting quitting from the Olympic Games, the events of PingPang and badminton are also facing the problem of being excluded from the Olympic Games, which attracts the wide attention in the sports circles in China. Wresting, as one of the three major events of the Summer Olympic Games, will be excluded from the Olympic Games which has caused a big stir within the international scope. And the root causes are that each time after the Olympic Games finished, the IOC will evaluate each event to maintain the justice of the Olympic Games and view the item setting from a developing perspective. The new events should replace

Corresponding author: Tao Liu, Dr., lecturer, research field: sports humanistic sociology. the old events to provide foundations for the sustainable development of the Olympic Games.

\section{The Evolution of the Item Setting of the Summer Olympic Games}

The competitive events of the Summer Olympic Games can be classified as max term, middle term and minor term but in the first Olympic Games held in 1896, there were only nine competitive events. Therewith, through constant innovation and improvement, the Olympic Games have bigger and bigger influence in the worldwide scope and the number of competitive events has also increased. For the setting of the competitive events of the Summer Olympic Games, the IOC has clearly stipulated that events such as track and field, basketball, football, gymnastics, weightlifting, swordplay, rowing, boxing, judo, wresting and swimming should at least be included in. Since the Olympic Games in Munich in 1972, all the above sports have been included in each Summer Olympic Games and the number of competitive events in each Olympic Games has also increased. There were 21 max 
terms and 195 minor terms in the Munich Olympic Games; 28 max terms and 300 minor terms in Sydney Olympic Games in 2000; 26 max terms and 300 minor terms in London Olympic Games in 2012. IOC has clear provision for the item setting of the Olympic Games that the number of max terms should be less than 28 and the minor terms less than 301 and the participants less than 10500 [1-8]. Male competitive events in Olympic Games should be spread in 75 countries of the world crossing four continents and female competitive events in Olympic Games should be spread in more than 40 countries crossing three continents. The minor terms of the competitive events are the max terms of the competitive events in Olympic Games and one competitive event can only be internationally recognized by obtaining the recognition in the aspects of participants and the regional scope and also being widely spread in at least 50 countries. It is easy to recognize that rapid growth of the item number of the Olympic Games can indirectly reflect a great influence of the Olympic Games itself. But because the scope of holding Olympic Games has become bigger and bigger, the burden of the host country become heavier and heavier, and the reformation and innovation for the future development of the Olympic Games have become people's necessary choice [9-16].

After Rogge taking charge of IOC in 2001, narrowing the scope of holding Olympic Games has become the primary task and reformation orientation. Although currently the effects of narrowing the scope are not obvious, the general orientation is right which thus will be bound to be represented in the future [17-21]. In 2007, the IOC announced one important reformation measure in 2007 that from 2020, the competitive events of the Summer Olympic Games will be narrowed to $25 \max$ terms and three contemporary max terms can be added appropriately according to the practical conditions. Therefore, in the future, there must be more competitive events being excluded from the Olympic Games and the wresting is exactly one of the events excluded from the Summer
Olympic Games under the backgrounds of reformation. Hence, the time of the Olympic Games' sustained expanding in scope has formally announced to be over but step into a totally new era [22-27].

\section{Controversies of Item Setting Standards in Summer Olympics}

\subsection{Deal with the Conflicts between Scale Reduction and New Items}

New games will be added into Olympics after some traditional items were eliminated. The conflict relationship between new items and the original ones will reflect their fierce competition. As a common activity, Olympic Games should reflect the organic integration of international features and national characteristics to realize the national equality, which is always emphasized. From the perspective of the current item setting of Olympics, the majority of them are Western traditional economic and sports items, and items of other regions are few. The phenomenon attributes to the close relationship between Olympic Games and Western culture, but the world and national characteristics still fail to be shown after the long development and innovation, which has been one of the top problems that should be improved at present. Therefore, only by leading more non-Western sport games into Olympics, can it develop comprehensively.

\subsection{Reflect Gender Equality in Item Setting}

In the process of development of Olympics, females had the opportunity of attending Olympics after experiencing many hardships. International Olympic Committee declared in 1924 that females could attend Olympics. Since then, more females attended Olympics, which was especially obvious in some small items. Promoting females to attend Olympics is always the reform orientation of International Olympic Committee. The number of sportswomen in Olympics increases sharply in recent years, and sportswomen could attend more games. The setting of women's boxing item in London Olympics in 2012 symbolized 
that females had the equal position with males in Olympics. But many items still need to be improved in the future. The phenomenon that females are banned to attend Olympics in some countries and areas runs in opposite directions with the spirit of national equality that International Olympic Committee advocates. Therefore, the concept of gender equality should be deepened now, and females should be encouraged to attend sports games.

\subsection{Coordinate Commercial Value and Social Value of Items}

The business operation model is the most obvious reform of Olympics, which invigorates Olympics. For example, business operation achieved success for the first time in Los Angeles Olympics in 1984, which brought strong social response and explored the business value and potential of Olympics. However, from another perspective, the application of the business model also has some severe weaknesses, which, to some extent, hinders the diffusion of Olympic spirit. Therefore, effectively balance business value and social value of Olympics under the times background becomes one of the top priorities of reform, which will have a profound influence on the future development of Olympics.

The development of Olympic Games is closely associated with social progress. If Olympic Games do not develop in the commercialized environment, its sustainable development will be impossible. Therefore, avoiding the excessive commercialization in the premise of bringing commercial operation into fully play is one of the problems that should be solved at first to reform Olympic Games. In addition, assessing economic value and social value of Olympic items in a scientific and reasonable way should be further explored and improved.

\subsection{Balance the Impact of Eurocentrism on Olympic Games}

From the perspective of Olympic sports items, most of these items originated from Europe, and have closed association with European culture. In addition, Eurocentrism could be reflected in these sports items. For example, horsemanship is ignored in Europe; most of local people have no idea about its basic rules; there is no professional horsemanship talent in Europe who can attend competitions. In Long Olympics, other countries only won 2 bronze medals in the horsemanship item. It is obvious that horsemanship Eurocentrism is serious. However, nobody appealed to cancel this item since horsemanship joined in Olympic Games. Similarly, other old Eurocentrism sports items such as fencing and kayak are still kept in Olympic Games. Europe takes the absolute advantage in these sports items. In addition, European representatives have the absolute discourse power in International Olympic Committee. 7 members come from Europe among all 8 International Olympic Committee members. Besides, Eurocentrism has profound influence on the setting of Olympic sports games. Even USA, the dominant power of Olympic Games, fails to replace Europe's advantage in Olympic Games.

There are clear standards on the selection of Olympic sports items. These sports items must be at least launched in males of 75 countries in 4 continents and females of 40 countries in 3 continents. However, apart from some main traditional items such as ball games, track and field events, and swimming, only a small amount of them come from other areas; most of Olympic sports items do not comply with the selection standards. For example, the new sports item-golf which was introduced in Rio de Janeiro Olympic Games in 2016 is a popular sport in Europe, but it is ignored in other countries and areas. Most of people do not know its basic rules and are not interested in watching golf. Therefore, the way to effectively balance the impact of Eurocentrism on the setting of Olympic sports item needs to be further improved in the modern age.

\subsection{Effectively Reduce the Impact of the Host Country on the Sports Item Setting}

It is common knowledge that the host country tends 
to have deep influence on the setting of Olympic items, which is one of the basic factors for the elimination or introduction of sports items. For example, Japan, the host country, introduced judo into Olympic Games in 1964. Japanese judo is well known in the world; Japan has strong competitiveness on judo; judo is the national-sport-skill in Japan. South Korea, the host country, introduced its characteristic item - kickboxing into Olympic Games in 1988 Seoul Olympic Games. USA, the host country, introduced women's football and beach volleyball into Olympic Games in 1996 Atlanta Olympic Games. As a result, America won two golden medals in these two new sports events.

\section{Analysis about the Value of the Item Setting of the Summer Olympic Games}

\subsection{The Setting of the Competitive Events Should Be Flexible}

There are two aims of narrowing the scope of the Olympic Games, the one is to relieve the burden of the host country and the other is to provide foundation and space for introducing more new events to the Olympic Games. And it has become certain tendency that there will be 25 max terms and three contemporary max terms in the future Olympic Games and the three contemporary max terms will be determined by the practical conditions which can reflect the flexibility of choosing events to the largest extend. Therefore, the wresting which has been excluded from the Olympic Games will compete with various events such as baseball, wushu and judo for the three quotas of contemporary max terms in the future Summer Olympic Games which proves that it still have chance to become the formal competitive events of the Summer Olympic Games [28-32].

\subsection{The Setting of Items Can Meet the Individual Needs of Teenagers}

Improving the competitive events becomes more attractive to teenagers and is always one of the major aims of the reformation of IOC and the IOC has always tried hard for this. Listing BMX as the competitive event of the Olympic Games is exactly to attract more teenagers. With the progression of society and the change of living environment, the elements that can attract teenagers have changed accordingly, and online games and TV programs seems more attractive for teenagers which has become an issue faced by all of us [33-36]. So to attract more teenagers, IOC will be committed to set more events that can attract teenagers' participating, and the teenagers are the source of the future development of the events. If the competitive events can not follow the time and satisfy the individual needs of teenagers, then the Olympic Games will no longer exist in the future multi-decades.

\subsection{The Popularity of Sports Events Focused on.}

Table tennis and badminton are two controversial sports events in Olympic Games in recent years. Other countries appeal to cancel these two sports events for multiple times because China keeps the absolute advantage in these two sports events and these two sports are played widely in China. For example, China only lost one golden medal in table tennis and badminton events in 2008 and 2012 Olympic Games. China even won all medals in three badminton world championships. It was not accidental for China to make such glorious achievements. These two sports events have been accepted in the world and are even regarded as the sports events for China. To promote table tennis event to be the professional event like NBA will be the main development direction in China. Only spreading the influence of China in this event, can China spread this sport in a wider range.

For the change of Olympic sports event evaluation standards, economic benefit and social benefit are not only the measurement standards any more. Higher social benefits should be created to attract all countries to join in the premise when economic benefit is valued. International Olympic Committee adds more measurement standards gradually, such as audience rating, ticket sales, and global popularity. It is obvious 
that the global popularity of sports events is still a major measurement standard now.

\section{Conclusion}

Above all, the item setting of the Olympic Games is the primary orientation of the current reformation of the Olympic Games and it is a necessary choice to make the competitive events more flexible and attract more new competitive events to enter into the Olympic Games which is also the mainstream of time's development. The item-setting of the Olympic Games can fully show the principles of the Olympic Games only by being more suitable to the world's trend of development and contribute to the world.

\section{Reference}

[1] Li, L. W. 2012. The Evolution Process and Development Tendency of the Item Setting of the Summer Olympic Games. Beijing Sports University.

[2] Li, W. L. 2012. "The Evolution Process and Development Tendency of the Item Setting of the Summer Olympic Games." Journal of Beijing Sport University (1): 34-43.

[3] Li, F. M. 2013. "The Setting Standards and Reformation Principle of the Items of the Summer Olympic Games: Studies Based on the Admission." Journal of Capital Institute of Physical Education (3): 260-2.

[4] Huang, X. B. 2013. "The Review and Tendency Prediction about the Evolution Process of the Item Setting of the Summer Olympic Games." Journal of JiLin Institute of Physical Education 11 (4): 59-62.

[5] Xue, H. W. 2013. "The Changing Process of the Item Setting of the Asian Games and the Analysis about Its Characteristics." Liaoning Sport Science and Technology 11 (5): 42-5.

[6] Huang, X. B. 2013. "The Macro Analysis about the Influential Factors of the Item Setting of the Summer Olympic Games." Journal of Hubei Sports Science (7): 586-8.

[7] Xuxin, L. L. 2013. "Studies on the Change of Item Setting of the Female Competitive Events in the Summer Olympic Games." Sports Culture Guide (9): 135-8.

[8] Wang, L. 2012. "Studies on the Item Setting of the Summer Olympic Games and the Big-scale Problems." Journal of Guiyang College (Natural Science) (2): 72-4.

[9] Li, K. Y., and Deng, X. 2010. "Practice of Sports Information Culture Communication and Analysis on Literature Communication-The Illustration on Olympics Library." Library Development 4: 43-6.
[10] Li, L., and Tian, L. 2015. "The Research of College Sports Information Management System Based on Component and the Application in Student's Management Work." International Journal of Hybrid Information Technology 8 (3): 375-86.

[11] Sun, T. H. 2014. "Research and Design on Sports Meeting Management System Based on Information Technology." Advanced Materials Research 971-973: 1953-57.

[12] Yan, H., and Wang, T. 2013. "Study on College Physical Education Management Information System Based on Support Vector Regression." Research Journal of Applied Sciences Engineering \& Technology 6 (22): 4254-8.

[13] Xu, J. M. 2014. "The Research of Ideological and Political Work Management System for College Students Based on J2EE." Applied Mechanics \& Materials 687-691: 2533-6.

[14] Slawson, S. E., Conway, P. P., and Cossor, J. 2012. "The Categorisation of Swimming Start Performance with Reference to Force Generation on the Main Block and Footrest Components of the Omega OSB11 Start Blocks." Journal of Sports Sciences 31 (5): 468-78.

[15] Tian, C. L. 2013. "Design and Research of University Fitness Club Operation Management Information System Based on Network Platform.” Shandong Sports Science \& Technology.

[16] Xu, J. M. 2014. "The Research of Ideological and Political Work Management System for College Students Based on J2EE." Applied Mechanics \& Materials 687-691: 2533-6.

[17] Slawson, S. E., Conway, P. P., and Cossor, J. 2012. "The Categorisation of Swimming Start Performance with Reference to Force Generation on the Main Block and Footrest Components of the Omega OSB11 Start Blocks." Journal of Sports Sciences 31 (5): 468-78.

[18] Shao-Jun, L. V., and Pei, X. C. 2015. "Basic Rules and Reform Research on the Event Development of Winter Olympic Games.” China Winter Sports 14 (9): 2104.

[19] Shao jun, L. U., Lin, X. M., and Chen, G. R. 2004. "Basic Rules of Olympic Event Development and Research on Event Reform." Journal of Beijing University of Physical Education.

[20] Joshi, C., Darwent, C., and Giese, K. 2009 "Transportation Modeling for the 2010 Winter Olympic Games." Conference \& Exhibition of the Transportation Association of Canada_Transportation in A Climate of Change.

[21] Hatfield, L. M., and Johnson, J. T. 2012. "A Discussion of Work Family Conflict and Related Theories in NCAA Division I Sports Information Professionals.” Journal of Contemporary Athletics 6 (1)

[22] Mazerolle, S. M., Bruening, J. E., and Casa, D. J. 2008. "Work-family Conflict, Part I: Antecedents of Work-family Conflict in National Collegiate Athletic Association Division I-A Certified Athletic Trainers." 
Journal of Athletic Training 43 (5): 505-12.

[23] Hatfield, L. M., and Johnson, J. T. 2013. “An Examination of WorkFamily Conflict in NCAA Division III and NAIA Sports Information Professionals." Journal of Applied Sport Management Research that Matters.

[24] Mazerolle, S. M., Ferraro, E. M., and Eason, C. M. 2013. "Factors and Strategies Contributing to the Work-Life Balance of Female Athletic Trainers Employed in the NCAA Division I Setting." Athletic Training \& Sports Health Care the Journal for the Prac.

[25] Mazerolle, S. M., Bruening, J. E., Casa, D. J., and Burton, L. J. 2008. "Work-family Conflict, Part II: Job and Life Satisfaction in National Collegiate Athletic Association Division I-A Certified Athletic Trainers." Journal of Athletic Training 43 (5): 513-22

[26] Baugh, C. M., Kiernan, P. T., and Emily, K. 2015. "Frequency of Head Impact Related Outcomes by Position in NCAA Division I Collegiate Football Players." Journal of Neurotrauma 32 (5): 314-26.

[27] Shirazi, A. 2003. "The Perceptions of Head Athletic Trainers in NCAA Division I, II, and III Member Institutions toward the Status of Alcohol Tobacco and Other Drug (ATOD) Prevention and Education Policies." Dissertation Abstracts International 64-12: 6043.

[28] Greve, L., and Dyson, S. J. 2014. "The Interrelationship of Lameness, Saddle Slip and Back Shape in the General Sports Horse Population." Equine Veterinary Journal 46 (6): 687-94.

[29] Mccann, S. 2014. "So You'd Like a Sport Psychology Consultant to Work with Your Team? Three Key Lessons Learned from Olympic Teams.” Olympic Coach 25 (3):
26.

[30] Rennie, C. 2014. "Agency Information Collection (VA National Veterans Sports Programs and Special Event Surveys Data Collection) Activity Under OMB Review." Federal Register 79 (47): 13741.

[31] Krasilnikov, V. L., Erlikh, V. V., and Mirgorodskaya, E. V. 2014. "New Approaches to Interpretation of Information Space in Sports Training of Swimmers on The Basis of Integration of Instrumental Technologies." Journal of Capital University of Physical Education and Sports.

[32] Mclamb, D. 2012. "Agency Information Collection (Authorization To Substitute a Claim of a Deceased Claimant); Activities Under OMB Review." Federal Register (164): 43228.

[33] Koufaki, D. P., and Kouidi, E. 2010. "Current Best Evidence Recommendations On Measurement And Interpretation Of Physical Function In Patients With Chronic Kidney Disease." Sports Medicine 40 (12): 1055-1074 (20).

[34] Ravana, D., Raman, S. N., and Ooi, P. P. 2007. "Analysis, Design and Development of Sports Information Portal: Supporting Participation in Sports Events." Journal of Applied Sciences Research (8): 757-63.

[35] Guah, M. 2009. "Case Study III: VLITP in Public Transport-Implementing OV-Chipcard in the Netherlands." Managing Very Large IT Projects in Businesses \& Organizations.

[36] Nan, X. H., Cui, W. F., and Yang, B. F. 2006. "Affection to the City Development and Winter Sports with Applying for the Winter Olympic Games of Harbin." Journal of Harbin Institute of Physical Education 24 (5): 7-9. 